\title{
The Influence of Technology on Employees' Work Life Balance in the Insurance Industry
}

\author{
Florence Githinji \& Dr Sussy Wekesa
}

\author{
Department of Entrepreneurship, Procurement \& Management, Jomo Kenyatta University of Agriculture \& \\ Technology P.O. BOX 62000-00200 Nairobi, Kenya, Florence Githinji P.O. Box 12471-00100 Nairobi.
}

\begin{abstract}
The insurance sector is one of the largest growing service providers in the country. Due to global dynamics and changes in the environment, emerging trends have continued to be experienced in the industry which employs a large number of workers who are unable to balance between work life and personal life. According to the African Reinsurance Corporation, the year's 2013 and 2014 the insurance industry experienced major changes due to emerging trends which led to low insurance uptake which in turn increased the number of casualties for insurers firms and reinsuring companies in Nairobi. There was an increase in acquisitions and mergers in this industry so as to remain afloat and competitive. This study explored the Influence of Technology on Employees' Work Life Balance in the Insurance Industry. The study drew samples from Nairobi County as the area is more open to research, and is the concentration centre for most insurance companies in Kenya. In this research 47 insurance companies in Nairobi County were studied. All insurance companies were covered so as to ensure that a high level of data was accurately obtained. Data was collected using questionnaires which had both open and closed ended questions. SPSS was used to ensure accurate evaluation and presentation. The study revealed that technology positively influenced the employees' work life balance in the insurance industry. There is need for the management to consider acquisition and use of technology like laptops which would help in working efficiently and new and innovative working methods to be at par with advancement in technology which would help enhance effectiveness.
\end{abstract}

Keywords - Employees, Work life balance, Insurance, Technology, Workers

\section{INTRODUCTION}

According to Anwar (2008), insurance is as an agreement whereby an insurer undertakes to pay a policyholder an amount of money on the occurrence of a specified event. The specified event must have some element of uncertainty about it. The uncertainty may either lie in the fact that although the event is bound to happen in the ordinary course of nature, the timing of its occurrence is uncertain; or the fact that the occurrence of the event depends upon accidental causes, and the event, therefore, may never happen at all. Insurers remain committed to capturing the large uninsured segment of the population and grow their market share. They are engaging in projects to improve emergent trends with improvement in technology, not only in order to support and optimize their current business operations but also to support customer centric projects. Digital technology and data analysis ability is significant not only to facilitate more real-time engagement with consumers but also to anticipate their changing needs and to manage risks more proactively rather than reactively (Price Waterhouse Coopers, 2015). Insurance in its modern form was unknown in Kenya until the early part of the 20th century. The history on the development of commercial insurance in Kenya is closely related to the historical emancipation of Kenya as a nation. With the conquest of Kenya as a British colony complete, settlers initiated various economic activities, particularly farming, and extraction of agricultural products (Kamau, 2003). These substantial investments needed some form of protection against various risk exposures. British insurers saw an opportunity in this and established agency offices to service the colony's insurance needs. Prosperity in the colony soon expanded from agencies to branch networks with more autonomy and expertise to service the growing insurance needs. In the years since independence, Kenya's insurance industry has flourished.

\section{STATEMENT OF THE PROBLEM}

The period between 2013 and 2014 was quite tumultuous in the Kenyan insurance industry with emerging trends coming up which forced companies into acquisition and mergers as the option to remain competitive. According to Association of Kenyan Insurers (AKI), this period experienced a wave of mergers and acquisitions due to emerging trends transcending around the globe leading to adverse effects to the society and to employees. The local industry and financial firms upped acquisition and mergers in order to grow the 
local firms' revenues consolidate their market share and expand regionally (AKI Annual Report, 2014). The development of global economy and human society had reached a tremendous high speed that has not been recorded so far in human history. Insurance companies have come under growing pressure to manage in an adequate manner, their financial profitability, and risk and consumer loyalty in a challenging and ever changing market. The year 2013 and 2014 experienced more advanced technological transaction methods such as mobile banking and introduction of fast money paying modalities such as Mpesa and banc assurance. These methods used to ease monetary transactions so as to be in line with all branches within the companies across the nation as well as in the region using centralized or aligned systems which are used inter-countries. The move by insurance firms to acquire and merge also led to changes in the social environment which led to new organizational restructuring, job re-engineering and ultimately downsizing of employees who had come of age hence retiring and rendering employees redundant. These changes increased pressure on employees, in terms of adjusting to the change itself and coping with its resulting effects. There was increased pressure from workloads and a need to develop new skills. The objective of this study is to establish. The Influence of influence of technology on Employees' Work Life Balance in the Insurance Industry

\section{LITERATURE REVIEW}

The researcher focused on two theories relevant to this study, which is the Border theory and Spill over theory. The Border theory considers the degree to which individuals are seen as integral members of their workplace communities as a critical indicator of the options and support they are likely to have in their efforts to maintain balance between the work and non-work spheres. In border theory, work and home represent two distinct spheres; Clark (2014) likened them to two countries, each with its own culture. Physical borders such as the walls of one's workspace, temporal borders such as one's work hours, and the psychological borders that dictate when one's thoughts, behaviors, technology and emotions are suitable in one domain and not the other, are all taken into account in border theory (Henderson et al., 2014). Spill over theory was first mentioned by Pleck (1977) when he analyzed work-family role systems and the spill over into both domains work life and family life (Naithani, 2010). Prior to the 1970s, society traditionally considered work and family domains separate entities; however, this notion has evolved into shared, interconnected platforms (Pleck, 1977). Hill et al., (2013) further supported Pleck's notions and suggested that what supports either negatively or positively the conditions in the work microsystem will spill over into the family microsystem, and what happens in the family microsystem will spill over into the work microsystem. Technology, time, energy, organization, and behavior can be strong determinants of work-life balance.

\subsection{Conceptual Framework}

\begin{tabular}{|c|c|}
\hline \multirow{3}{*}{$\begin{array}{l}\text { Technology } \\
-\quad \text { Globalization } \\
\text { - } \quad \text { Virtual Networking }\end{array}$} & Work Life Balance \\
\hline & - Increased efficiency \\
\hline & - Motivation \\
\hline
\end{tabular}

\section{Figure 1}

According to Thompson et al., (2010), accurate and timely information about daily operations is essential if managers are to gauge how well the strategy execution process is proceeding; and that information systems need to cover broad areas such as customer data, operation data, employee data, supplier or partner or collaborative ally data, and the financial performance data. Information, communication and technology increases in deregulation and associated moves towards the 24 hours and 7 days society, the temporal range of working hours has expanded leading to an expansion of flexible and long working hours. When technology is changing, organizational survival requires that managers quickly adopt and apply new technologies to innovate and apply new technologies to more new products. The rate of technological change in an industry particularly the length of product life cycle determines how important it is for managers to innovate. Emerging trends have created improvements in communication due to the need to communicate across board and around the globe to the organizations staff as well as customers. Technological innovations have resulted in a wide range of options for working from satellite offices or from remote locations, all collectively known as telework (Kornad et al., 2012). The increase in technological competence as an emerging trend in the environment and in organizations specifically shows that more and more employees are able to work remotely. Technological and telecommunications advances such as portable computers, mobile phones have also made possible working 
longer hours and performing job tasks in a variety of locations (Lewis et al., 2005). Virtual work programs may foster a greater sense of work-life balance and increased productivity in the workplace. Technological advances provide workers with increased location flexibility. Employees may feel an obligation to check e-mail and work all hours of the day into the evening, on the weekends, and while on vacation (Adkins et al., 2014). Improved means such as; video conferencing, web cam and lately via the social medias' face book, twitter, instagram and other blogs have opened up such that information and varied opinions can be collected addressing issues and challenges from any location. However according to Prasopoulou et al., (2006), advent of technology not always have positive impact on the employees, asserted that expectation from an employee to be available 24 hours a day, can be challenging as well as result in work life conflict.

\section{RESEARCHER METHODOLOGY}

A quality research design is dependent on the interaction between data collection and data analysis to allow for meaning to be explored and clarified (Saunders et al., 2012). This study used cross sectional survey design and descriptive research design methods. A survey is an attempt to collect data from members of a population in order to determine the current status of that population with respect to one or more variables. Cross-sectional research involves using different groups of people who differ in the variable of interest but share other characteristics, such as socioeconomic status, educational background, and ethnicity (Sekaran et al., 2010). Orodho (2003) and Kothari (2004) describe a descriptive survey design as a design that sought to portray accurately the characteristics of a particular individual, situation or a group. The target population of this study was all the insurance companies in Nairobi County. According to the IRA in 2014 there were 47 insurance companies who have their head offices in Nairobi County and focus were on these companies. Sampling method was used due to its viability to identify respondents who participated in the study. The information was obtained by collecting data through the administration of questionnaires. The researcher used this method to validate the results of the respondents obtained. Drop and pick method was used for data collection. Before the actual study, a pilot study was conducted. According to Orodho (2003), a pilot test helps to test the reliability and validity of data collection instruments. The data obtained was analyzed using both quantitative and qualitative approaches. The researcher used bar charts, statistical computations, calculations and oral narratives based on subjective summary of phenomena were put to great use during the analysis of data.

\section{Research Findings}

\subsection{Response Rate}

The target population of this study was all the insurance companies which were 47 in Nairobi County. The study targeted a sample size of 47 respondents in which 42 out of the total 47 filled in and handed in their questionnaires. From the data collected the total actual response percentage was $89.4 \%$ while the remaining $10.6 \%$ did not return their questionnaires on time.

The researcher analyzed the data collected and presented both quantitative and qualitative as follows:

\subsection{Reliability Analysis}

A pilot study was carried out to determine reliability of the questionnaires. Reliability analysis was subsequently done using Cronbach's Alpha which measures the internal consistency by establishing if certain items within a scale measure the same construct. According to Kimberlain et al., (2008) Cronbach Alpha is the most recommended method to test reliability.

Table 1: Reliability Coefficients

\begin{tabular}{lcc}
\hline Scale & Cronbach's Alpha & Number of Items \\
\hline Technology & 0.818 & 6 \\
\hline
\end{tabular}

Cronbach's Alpha was calculated by application of SPSS for reliability analysis. The value of the alpha coefficient ranges from 0-1 and may be used to describe the reliability of factors extracted from dichotomous and or multi-point formatted questionnaires or scales. A higher value shows a more reliable generated scale. Cooper et al., (2008) indicated 0.7 to be an acceptable reliability coefficient.

\subsection{Demographic Information}

From the findings on Fig. 2, 62.7\% of the respondent indicated their highest level of education as Bachelor's degree, $23.3 \%$ of the respondents indicated that their highest level of education was Masters Degree and 14\% of 
the respondents indicated their highest level of education was Diploma level. This is an indication that most of the respondents were well educated and that they were in a position respond to research questions with ease and also handle the work assigned. It is noted that the insurance industry highly embraces personnel who have high education qualifications from the findings.

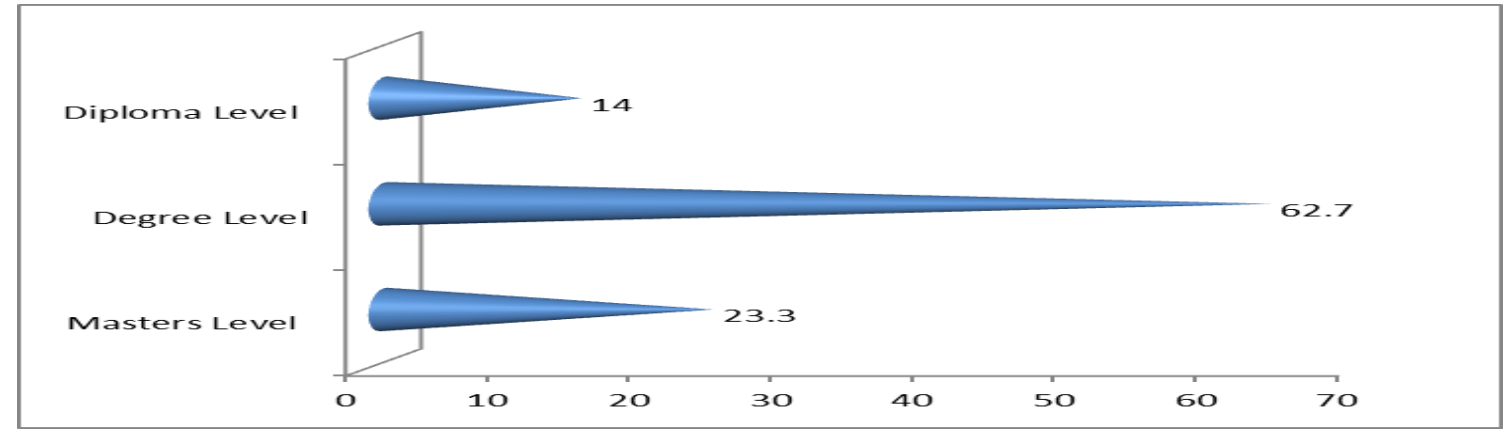

Figure 2: Respondent Level of Education

$51.2 \%$ of the respondents were married, $41.9 \%$ of the respondents indicated they were single, and $2.3 \%$ of the respondents indicated they were separated and $4.7 \%$ were divorced as per the Fig. 3 below.

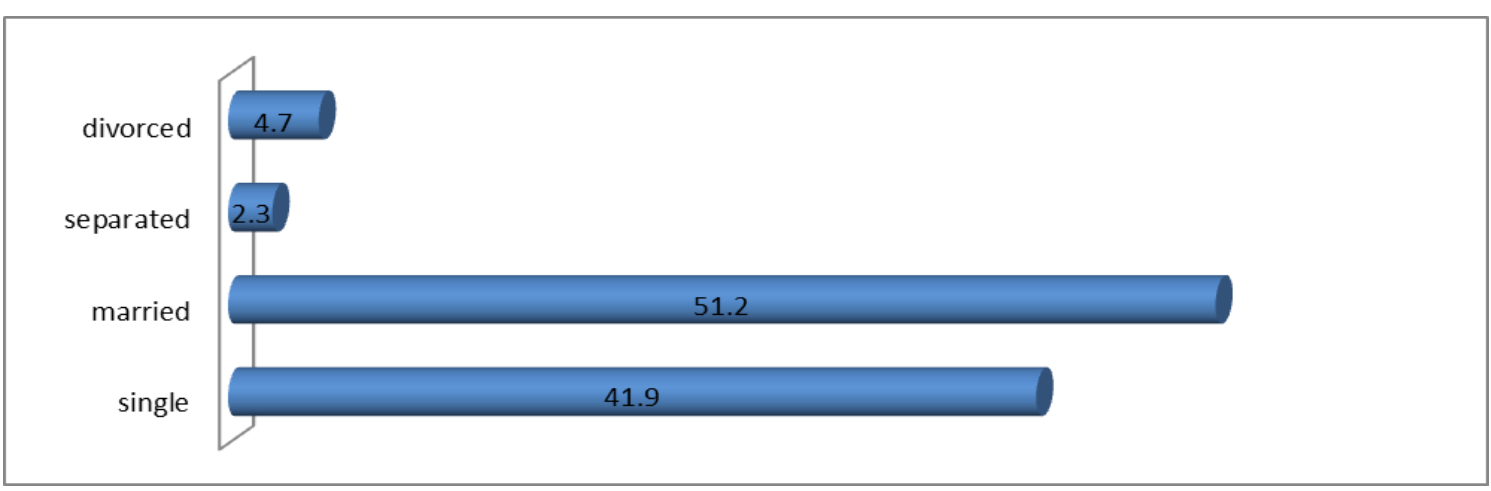

Figure 3: Marital Status of the Respondents

From Fig. 4 below majority of the respondents as shown by $30.2 \%$ indicated that they had 2 children, $25.6 \%$ indicated that they had 1 child whereas $20.9 \%$ indicated that they had no children, $18.6 \%$ indicated that they had 3 children and $4.7 \%$ indicated having 4 children and more. This is an indication that respondents would be capable to respond to the questions with ease as they have dual roles in the workplace as well as take care of children at home.

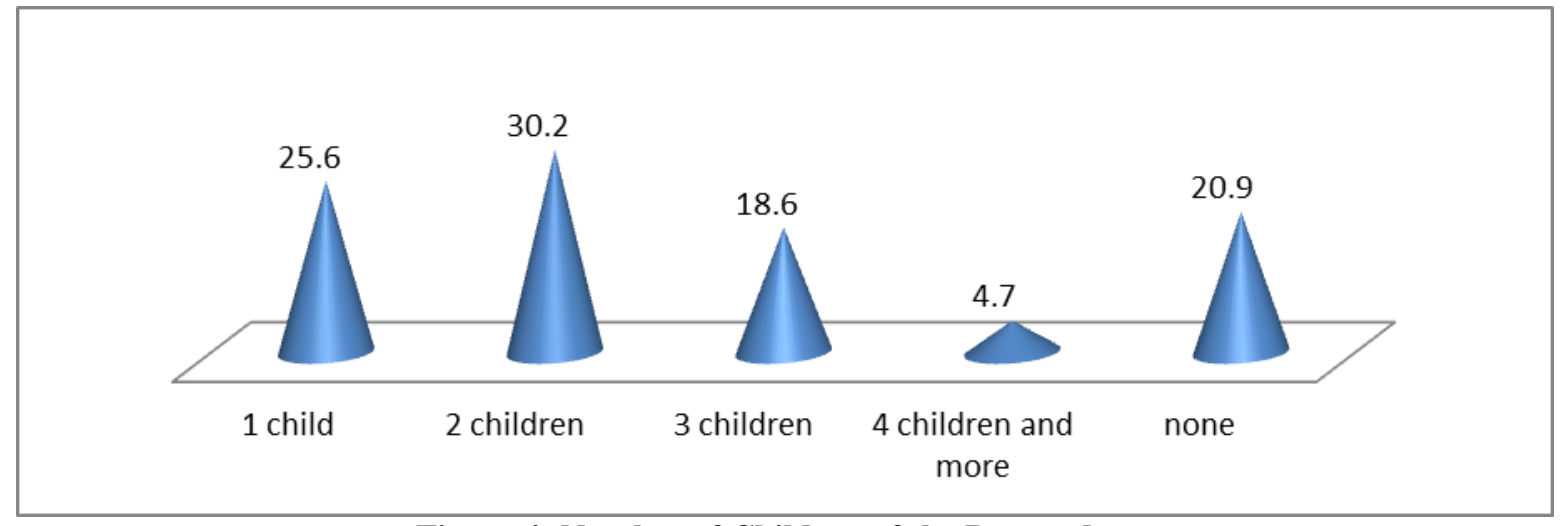

Figure 4: Number of Children of the Respondents

\subsection{Descriptive Statistics}

On the respondent's level of agreement with the following statements on technology as an influence of emerging trends on employees' work life balance in the insurance industry in Nairobi County. The study found out that majority of the respondents agreed that carrying work out of the office affects work balance as shown 
by a mean of 2.90; and that the organization communicates to its members and customers through telephone, emails, postal as shown by a mean of 1.79 . One carries unfinished workloads out of the office as shown by a mean of 1.58, that one worries because of lack of network coverage and to what extent as shown by a mean of 1.47. Technology advances like laptops helped in working efficiently as shown by a mean of 1.42 and that the company provides new and innovative working as shown on the Table2 below.

Table 2: Effect of Technology on work life balance

\begin{tabular}{|l|l|l|}
\hline Statements & & \\
& & \\
\hline $\begin{array}{l}\text { If the company provides new and innovative working methods to be at par with advancement in } \\
\text { technology }\end{array}$ & 1.05 & 0.21 \\
\hline To what extent has technology advances like laptops helped in working efficiently & 1.42 & 0.73 \\
\hline If one carries unfinished workloads out of the office & 1.58 & 0.50 \\
\hline Extent to which carrying work out of the office affects work balance & 2.90 & 1.17 \\
\hline How the organization communicates to its members and customers & 1.79 & 0.77 \\
\hline If one worries because of lack of network coverage and to what extent & 1.47 & 0.70 \\
\hline
\end{tabular}

\subsection{Regression Analysis}

The regression analysis for technology in relation to employees' work life balance was computed at $95 \%$ confidence level and summarized below.

Table3: Technology in relation to globalization

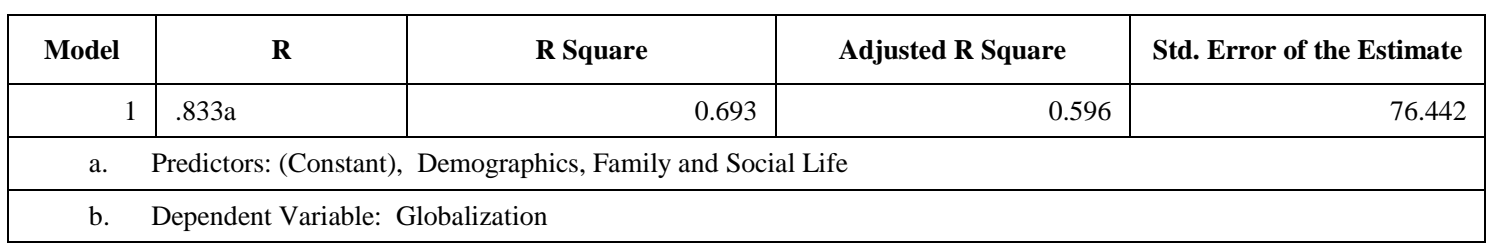

The regression analysis for demographics, family and social in relation to globalization found a coefficient of determination of 0.693 as per the Table 3 above. This means that $63.9 \%$ variability of globalization is attributed to demographics, family social life. The other variation of $30.7 \%$ is explained by variation in other factors.

Table4: Technology in relation to globalization

\begin{tabular}{|c|l|c|c|c|}
\hline Model & \multicolumn{1}{|c|}{$\mathbf{R}$} & R Square & Adjusted R Square & $\begin{array}{c}\text { Std. Error of the } \\
\text { Estimate }\end{array}$ \\
\hline 1 & $.816 \mathrm{a}$ & 0.666 & 0.63 & 0.48897 \\
\hline c. $\quad$ Predictors: (Constant), Demographics, Family and Social Life \\
\hline d. Dependent Variable: Virtual banking
\end{tabular}

The coefficient of determination ( $\mathrm{R}$ square) was found to be 0.666 after analysis of technology in relation to virtual banking. This means that 0.666 variability in virtual banking can be attributed to demographics, family and social life in the insurance industry in Nairobi County. The other variation of $33.4 \%$ is explained by variation in other factors.

\section{CONCLUSION}

The study found out that carrying work out of the office affects work balance; it also found out those carrying unfinished workloads out of the office has a significant negative effect. The organization medium of communication to its members and customers is through telephone, emails, post. Majority of respondents worry when there is lack of network coverage. There is a significant extent in improvement in productivity whereby technology advances like laptops have helped in working efficiently and that the company provides new and innovative working methods to be at par with advancement in technology. The findings of the study were in line with Thompson et al., (2010) who states that accurate and timely information about daily operations is essential if managers are to gauge how well the strategy execution process is proceeding; more emphasis was also in information systems need to cover broad areas such as customer data, operation data, employee data, supplier or partner or collaborative ally data, and the financial performance data. Information, communication and 
technology increases in deregulation and is more associated moves towards the 24 hours and 7 days society, the temporal range of working hours has expanded leading to an expansion of flexible and long working hours

\section{ACKNOWLEDGEMENTS}

I also wish to thank all those who have made this academic journey possible through their support. To my entire family for their moral support and encouragement and for allowing me to take time off and concentrate on my research project as I wouldn't have made it this far without them. I would wish to express my sincere gratitude to my Supervisor, Dr. Suzzy Wekesa for her scholarly support, patience, guidance; selfless dedication and encouragement in the planning, development and making this project a reality. It is without a doubt that her perpetual sacrifice; constructive criticism and comments shaped this report. Finally, I acknowledge the contribution of my colleagues and classmates, and more specifically Esther Mwangi and Purity Munyiri for the constructive meetings we had outside the institution, their critics and positive input.

\section{REFERENCES}

[1] Anwar, Habiba (2008). Islamic Economic Environment: A Guide for International Business and Investment. GMB Publishing Ltd., United Kingdom.

[2] Price water house coopers, (2016). Journal Insurance Industry Analysis.

[3] Clark, L. A., Karau, S. J., \& Michalisin, M. D. (2012). Telecommuting attitudes and the 'big five' personality dimensions. Journal of Management Policy and Practice, 13(3), 31-46.

[4] Naithani, P. (2010). Overview of Work-life balance discourse and its relevance in current economic scenario, Asian Social Science, 6(6), 148-155.

[5] Thompson, J., Arthur A., Strickcan, A. J. and Gamble, J. E. (2010). Crafting and Executing Strategy. New York, NY.

[6] Konrad, A. M., \& Yang, Y. (2012). Is using work-life interface benefits a career-limiting move? An examination of women, men, lone parents, and parents with partners, Journal of Organizational Behavior, 33(7), 1095-1119.

[7] Lewis, S. \& Cooper, L. (2005) Work-life Integration: Case Studies of Organisational Change, Wiley: Chichester.

[8] Adkins, C., \& Premeaux, S. A. (2014). The use of communication technology to manage work - home boundaries, Journal of Behavioral \& Applied Management, 15 (3), 82-100.

[9] Saunders, M., Lewis, P., \& Thornhill, A. (2012) Research Methods for Business Students. Harlow; Pearson.

[10] Sekaran, U., \& Bougie, R. (2010). Research Methods for Business: A Skill Building Approach (5th ed.). London: John Willey \& Sons.

[11] Orodho AJ (2003). Essentials of Educational and Social Science. Research Method. Qualitative and Quantitative Approaches Nairobi: Acts Press.

[12] Kothari C (2004). Research Methodology: Methods and Techniques, 2nd edition. New age International Publishers, New Delhi, India.

[13] Kimberlin, C., Winterstein, A., (2008). Validity and reliability of measurement instruments used in research. 